15. Li, D. M. Stowage, securing and management of vehicles loaded onboard Ro/Ro passenger ships [Text] / D. M. Li // China Maritime Safety. - 2008. - Vol. 4. - P. 46-49.

16. Shybaev, A. H. Modelyrovanye zahruzky sudna pri linejnoj forme sudohodstva [Text] / A. H. Shybaev // Optimizacija proizvodstvennyh processov. - 2001. - Vol. 4. - P. 181-184.

17. Shybaev, A. H. Modelyrovanye zahruzky kontejnerovoza na lynyy [Text] / A. H. Shybaev, Yu. Y. Kyryllov // Visnyk Odes'koho natsional'noho mors'koho universytetu. - 2008. - Vol. 25. - P. 134-145.

18. Lan, H. Optimization of the Container Loading Sequences Based on Actual Constraints [Text] / H. Lan, Z. Bian, Z. Jin // ICLEM. - 2014. - P. 989-994. doi: 10.1061/9780784413753.150

19. Xiang, F. The Graded Optimization Models and Algorithms for the Container Multimodal Transportation Planning [Text] / F. Xiang, W. Sun, Z. Jin // Logistics. - 2009. - P. 1045-1054. doi: 10.1061/40996(330)149

Розглядається задача числової оцінки об'екта в нечіткій постановці. Запропоновано евристичні правила визначення колективної числової оцінки об'єкта, які дозволяють врахувати ступені впевненості експертів у їх оцінках. Побудовано модель задачі прогнозування часових рядів як задачі визначення числової оцінки об'єкта. Розроблено метод визначення прогнозних значень часових рядів з використанням результатів експертних опитувань

Ключові слова: нечітка задача числової оцінки об'єкта, евристика, експерт, прогнозування иасових рядів

\section{口-}

Рассматривается задача числовой оченки объекта в нечеткой постановке. Предложены эвристические правила определения коллективной числовой оценки объекта, которые позволяют учесть степени уверенности экспертов в их оценках. Построена модель задачи прогнозирования временных рядов как задачи определения числовой оценки объекта. Разработан метод определения прогнозных значений временных рядов с использованием результатов экспертных опросов

Ключевые слова: нечеткая задача числовой оценки объекта, эвристика, эксперт, прогнозирования временных рядов
UDC 004.023:519.816

DOI: $10.15587 / 1729-4061.2016 .70515$

\title{
DESIGNING FUZZY EXPERT METHODS OF NUMERIC EVALUATION OF AN OBJECT FOR THE PROBLEMS OF FORECASTING
}

\author{
O. Mules a \\ Candidate of Technical Science, \\ Associate Professor* \\ E-mail: mulesa.oksana@gmail.com \\ F. G e che \\ Doctor of Technical Sciences, \\ Professor, Head of the Department* \\ E-mail: fgeche@hotmail.com \\ * Department of cybernetics and \\ applied mathematics \\ Uzhgorod National University
}

Narodna Square, 3, Uzhhorod, Ukraine, 88000

\section{Introduction}

Poor structure of considerable part of modern applied problems and tasks, the lack of reliable and representative input data and the possibility to consider non-standard and unpredictable factors during their solving underlie the need to apply such an approach as the expert surveys. The problem of determining numerical evaluation of an object plays an important role among the tasks where the expert opinions are largely used to solve them. As a rule, certain complex immeasurable characteristics of the object are assessed, which requires professional knowledge and experience of the experts. The theory of decision making described a number of rules that determine collective evaluation which are based on the processing of both the expert assessments and the values that characterize degrees of expert group competence.

Subjective nature of expert assessments, in its turn, predetermines a possibility to use the apparatus of fuzzy sets prior to collective evaluation. The successful application of models and methods that are based on fuzzy logic allows improving the results of solutions of such problems by a specific criterion.

System analysis of time series forecasting methods detected a class of economical, medical and sociological problems that are needed to consider not only the internal regularity of the time series but the external significant factors too, in the design of efficient methods of forecasting. Taking into account the fact that while solving the practical tasks, it is not always possible to formalize the action of external factors due to their sporadic and unpredictable nature, it would be expedient to involve the experts to evaluate them, which makes it possible to consider additional factors which can have a significant impact on the investigated phenomenon.

Thus, a development of heuristic models and forecasting methods of time series under real conditions, which allow taking into account the experts' (group of experts) assessments, is an actual and practical important task. 


\section{Analysis of scientific literature and the problem statement}

The task of numeric evaluation of an object belongs to the problems of the theory of decision making. A lot of methods of determining the numeric evaluation of the object are known, the mathematical calculations of which are included in $[1,2]$. As is shown in $[2,3]$, some of them take into account such characteristics of a person who makes a decision and experts as propensity to risk, the level of optimism, etc. The paper [4] is devoted to axiomatic and mathematical properties of expert methods of decision making, including methods for the determination of the numerical evaluation of the object that is a continuation of the classical theory of decision making.

Analysis of modern scientific publications on the theory of decision making shows that the research and application of problems of the determination of the numeric object evaluation under fuzzy conditions is rather actual. Thus, methods of processing of fuzzy expert information are offered in [5], which allow presenting subjective opinions of experts in the form of fuzzy sets. Such methods, as a rule, allow including the questions in the expert form, where words or opinions can be considered as the answers to those questions. The paper [6] contains fuzzy analogues of the methods of collective expert assessments that allow considering different types of inaccuracies and ambiguity in the experts conclusions. Possibilities and the ways of applying of fuzzy expert methods are shown in the work [7].

Also, coefficients of experts' competence, as a rule, influence the final evaluation significantly, which are aggregated evaluation of such indicators as the expert professionalism, confidence degree for the expert, the results of expertises made by him/her in the past, etc. There are different methods of defining the competence of experts. Thus, the paper [8] contains the classification and analysis of a priori methods of determining experts' competence. According to this classification, a priori methods are divided into heuristic (methods of self-assessment, mutual evaluation), experimental and documentary. The work [9] is devoted to the posteriori methods of defining the experts' competence. A separate group includes methods based on the axiom of unbiasedness which is described in the paper [10]. The method of calculation of confidence for an expert based on the method of paired comparisons is shown in the work [11].

The work [12] deals with research and design of forecasting methods of time series. As a rule, statistic and intuitive approaches are used in the design of methods of forecasting [13]. However, in the case when the forecasting is made under conditions of the action of random poor formalized factors, it would be expedient to use the results of expert surveys as the additional source of information.

It would be expedient to design such methods of time series forecasting that provide a possibility of simultaneous consideration of both the internal regularity of the time series and the impact of systematic and unsystematic poor formalized random factors on it.

\section{The purpose and objectives of the study}

The aim of the research is to develop heuristic rules of defining the numeric evaluation of the object based on fuzzy expert assessments to improve decision making in the cases when the results of expert surveys are used for forecasting and applying certain numerical characteristics of the objects.

To achieve the set goal, the following tasks were defined:

- to build a mathematical model of the problem of defining the numeric object evaluation;

- to develop heuristic rules of defining the numeric object evaluation that make it possible to consider certain subjective characteristics of experts and their assessments as well;

- to explore a possibility of using fuzzy experts assessments to solve the problems of time series forecasting;

- to carry out experimental validation of the developed rules of the numeric evaluation of the object.

\section{Setting and analysis of the problem of the numeric evaluation of the object}

Consider the problem of numeric object evaluation [2]: set the object $\mathrm{O}$.

It is necessary to determine its numeric evaluation by some criterion $\mathrm{K}$.

Engage a group of experts $\mathrm{k}$ to determine the evaluation:

$\mathrm{E}=\left\{\mathrm{E}_{1}, \mathrm{E}_{2}, \ldots, \mathrm{E}_{\mathrm{k}}\right\}$, their competence coefficients are, accordingly

$$
\alpha_{1}, \alpha_{2}, \ldots, \alpha_{k}, \text { where } \alpha_{i} \in[0 ; 1] \text { and } \sum_{i=1}^{k} \alpha_{i}=1 \text {. }
$$

Experts' competence coefficients can be set by a person who makes decisions or defined with the help of known methods [8-11].

Consider the case when each of the experts $E_{i}(i=\overline{1, k})$ sets the following values during the numeric evaluation of the object:

- the interval of changing of the object evaluation $\left[\mathrm{a}_{1 \mathrm{i}}, \mathrm{a}_{2 \mathrm{i}}\right]$;

$-\mu_{1 i}, \mu_{2 \mathrm{i}} \in[0 ; 1]$ - degrees of confidence in their evaluation $\mathrm{a}_{1 \mathrm{i}}$ and $\mathrm{a}_{2 \mathrm{i}}$ accordingly;

- evaluation $\bar{a}_{\mathrm{i}} \in\left[\mathrm{a}_{1 \mathrm{i}}, \mathrm{a}_{2 \mathrm{i}}\right]$, degree of confidence $\bar{\mu}_{\mathrm{i}}$ where $\left(\bar{\mu}_{\mathrm{i}} \in[0 ; 1]\right)$ is the highest.

It would be possible to use heuristics at the degree of preliminary processing of expert assessments that allow excluding from consideration those experts with the certain features in their degree of confidence [14].

The following heuristics are proposed:

Heuristics 1. Excluding those experts from the group $\mathrm{E}$ who have the coefficient of confidence in their evaluations lower than the predetermined level. That is:

$$
\mathrm{E}:=\mathrm{E} \backslash\left\{\mathrm{E}_{\mathrm{i}}\right\}, \forall \mathrm{i}=\overline{1, \mathrm{k}}: \bar{\mu}_{\mathrm{i}} \leq \Delta,
$$

where $\Delta \in(0 ; 1)$ is the predetermined level.

Heuristics 2. Excluding those experts from the group E who have the coefficient of confidence in their evaluations higher than the predetermined level. That is,

$$
\mathrm{E}:=\mathrm{E} \backslash\left\{\mathrm{E}_{\mathrm{i}}\right\}, \forall \mathrm{i}=\overline{1, \mathrm{k}}: \min \left\{\mu_{1 \mathrm{i}}, \mu_{2 \mathrm{i}}\right\}>\bar{\Delta},
$$

where $\bar{\Delta} \in(0 ; 1)$ is the predetermined level.

Heuristics 3. Excluding those experts from the group E who are equally confident in their evaluations. That is,

$$
\mathrm{E}:=\mathrm{E} \backslash\left\{\mathrm{E}_{\mathrm{i}}\right\}, \forall \mathrm{i}=\overline{1, \mathrm{k}}:\left|\bar{\mu}_{\mathrm{i}}-\min \left\{\mu_{1 \mathrm{i}}, \mu_{2 \mathrm{i}}\right\}\right|<\varepsilon,
$$

where $\varepsilon$ is the predetermined value of the range of confidence degrees. 
Assume that the group of experts has the following view after doing Heuristics 1-3: $\mathrm{E}=\left\{\mathrm{E}_{1}, \mathrm{E}_{2}, \ldots, \mathrm{E}_{\mathrm{n}}\right\} \quad(\mathrm{n} \leq \mathrm{k})$ and define the coefficients of confidence of appropriate experts $(i=\overline{1, n})$ through $\alpha_{i}$. Calculate the total competence of the group of experts $\mathrm{E}$ by the formula:

$$
\bar{\alpha}=\sum_{\mathrm{i}=1}^{\mathrm{n}} \alpha_{\mathrm{i}}
$$

If the compiled group of experts is incompetent (i. e. $\bar{\alpha}$ is not high enough according to the point of view of a person who makes decisions), then further task to solve the problem of defining the numeric object evaluation would be inexpedient. In the opposite case, it is proposed to fulfill normalization of the values of experts' competence coefficients by the following formula:

$$
\alpha_{i}:=\frac{\alpha_{i}}{\sum_{i=1}^{n} \alpha_{i}}
$$

Experts' coefficients of competence normalized by (4) are used to determine the numeric evaluations of objects.

\section{Fuzzy rules of defining collective evaluation}

Next step during the determination of the numeric object evaluation is formation of fuzzy set $A_{i}=\left\{\left(x, \mu_{i}(x)\right)\right\}$ for every expert $E_{i} \in E$ [2]. Membership functions of fuzzy sets are determined by the following rule:

$$
\mu_{i}(x)= \begin{cases}0, & \text { if } x<a_{1 i} ; \\ \mu_{1 i}, & \text { if } x=a_{i 1} ; \\ a_{1 i} x+b_{1 i}, & \text { if } x \in\left[a_{i 1}, a_{i}\right] \\ \mu_{i}, & \text { if } x=\overline{a_{i}} ; \\ a_{2 i} x+b_{2 i}, & \text { if } x \in\left[\bar{a}_{i}, a_{2 i}\right] \\ \mu_{2 i}, & \text { if } x=a_{2 i} ; \\ 0, & \text { if } x>a_{2 i}\end{cases}
$$

Coefficients $a_{1 i}, a_{2 i}, b_{1 i}, b_{2 i}$ are determined by solving the appropriate systems of linear algebraic equations.

As is seen from (5), in general case membership functions $\mu_{\mathrm{i}}(\mathrm{x})$ will have piecewise linear form.

The following rules are proposed to determine a collective numeric evaluation of the object:

Rule 1. Fuzzy set of collective numeric object evaluation $\mathrm{C}=\{(\mathrm{x}, \mathrm{M}(\mathrm{x}))\}$ with function membership $\mathrm{M}(\mathrm{x})$ is calculated in the following way:

$$
\mathrm{M}(\mathrm{x})=\sum_{\mathrm{i}=1}^{\mathrm{n}} \alpha_{\mathrm{i}} \mu_{\mathrm{i}}(\mathrm{x})
$$

The algorithm of the calculation of membership function of the resulting fuzzy set should boil down to defining the total of the corresponding membership functions in the intervals of their monotony.

Rule 2 . Form the fuzzy set $\mathrm{C}=\{(\mathrm{x}, \mathrm{M}(\mathrm{x}))\}$ by the rule:

$$
M(x)=\max \left\{\mu_{i}(x): \sum_{j=1, n: \mu_{j}(x) \geq \mu_{i}(x)} \alpha_{j}>0.5, i=\overline{1, n}\right\},
$$

i. e., the membership function as the degree of confidence in the value of the numeric evaluation will signify the degree of confidence of the competent majority of the experts.

Rule 3. Determine dephasified numeric evaluation for each expert. Let $\mathrm{a}_{\mathrm{i}}$ is the evaluation of the $\mathrm{i}$-th expert. Next, perform calculations similar to the accurate case.

Rule 4. According to the accurate methods of determining collective numeric object evaluation, calculate the total of fuzzy numbers:

$$
\begin{aligned}
& \mathrm{C}=\alpha_{1} \mathrm{~A}_{1}+\alpha_{2} \mathrm{~A}_{2}+\cdots+\alpha_{\mathrm{n}} \mathrm{A}_{\mathrm{n}}= \\
& =\bigcup_{c \in S_{c}} \max _{\substack{\left(a_{1}, a_{i}, \ldots, \ldots a_{n}\right): \\
a_{i} \in S_{A_{i}}, \sum \alpha_{i} a_{i}=c}} \min \left\{\mu_{1}\left(a_{1}\right), \mu_{2}\left(a_{2}\right), \ldots, \mu_{n}\left(a_{n}\right)\right\},
\end{aligned}
$$

where $S_{A_{i}}$ are the carriers of corresponding fuzzy sets $\mathrm{A}_{\mathrm{i}}, \mathrm{i}=\overline{1, \mathrm{n}} ; \mathrm{S}_{\mathrm{C}}$ is the carrier of fuzzy set $\mathrm{C}$.

To determine collective numeric evaluation, it is proposed to use one of the following correlations:

$$
\begin{aligned}
& x^{*}=\frac{\sum_{i=1}^{m} x_{i}}{m}, \\
& x^{*}=\max _{x}\left\{\operatorname{Arg} \max _{x}\{M(x)\}\right\}, \\
& x^{*}=\min _{x}\left\{\operatorname{Arg} \max _{x}\{M(x)\}\right\},
\end{aligned}
$$

where $x_{i} \in \operatorname{Arg} \max _{x}\{M(x)\}, m$ is the capacity of the set

$$
\operatorname{Arg} \max _{\mathrm{x}}\{\mathrm{M}(\mathrm{x})\} \text {. }
$$

Depending on the nature of the considered problem, the formulas (9)-(11) provide the alternative choice of the numeric evaluations of the object for a person who makes a decision.

\section{Application of fuzzy rules of defining collective evaluation of the object to the problem of time series forecasting}

Consider the problem of time series forecasting:

It is necessary to determine the values $y(n+1), \ldots$, $y(n+T)$ based on the elements of time series $y(1), y(2), \ldots$, $y(t), \ldots, y(n)$, where $T$ is the step of forecasting.

Generally, it is necessary to determine a forecasting model during forecasting of time series i.e. a functional dependency that can be written down as follows (with the accuracy to random component $\varepsilon_{\mathrm{t}}$ ):

$$
y(t)=F(y(t-1), y(t-2), \ldots)+\varepsilon_{t} .
$$

Models and methods used frequently to solve the problem of time series forecasting include:

Winters method that takes into account season components;

- regression model of forecasting;

- autoregression method;

- method of least squares with weights;

- Brown forecasting models, etc.

The method of synthesis of a forecasting scheme based on the basic forecasting models with underlying mechanism 
of competition in a given period of time was proposed in the papers $[13,15]$ and the resulting forecasting scheme is a convex linear combination of the winner' models with respective weight coefficients.

As shown in the papers [13, 15], this approach allows increasing the quality of time series forecasting.

Classic methods and schemes that are formed on their basis, in many cases do not consider the impact of poor formalized external random factors in full, for example, during forecasting social - economic and medical indicators.

Such external factors do not have permanent or seasonal character in certain problems and should be forecasted themselves, however, they can produce significant effect on the predicted value and thus decrease the accuracy of the forecast which can be obtained by the methods of forecasting. It would be expedient to use the results of expert surveys for such problems as one of the sources of information for solving a forecasting task.

A model of time series forecasting is proposed with an "expert block" as a component of it.

Thus, let there be the time series $\mathrm{y}(1), \mathrm{y}(2), \ldots, \mathrm{y}(\mathrm{t}), \ldots$, $\mathrm{y}(\mathrm{s})$ where it is necessary to consider the value $\mathrm{y}(\mathrm{s}+1), \ldots$, $\mathrm{y}(\mathrm{s}+\mathrm{T})$, where $\mathrm{T}$ is the step of forecasting.

Let there be a group of $n$ experts: $E=\left\{E_{1}, E_{2}, \ldots, E_{n}\right\}$, who have the coefficients of competence, accordingly, $\alpha_{1}, \alpha_{2}, \ldots, \alpha_{n}\left(\alpha_{i} \in[0 ; 1]\right)$ and $\sum_{i=1}^{n} \alpha_{i}=1$.

Each of the experts $E_{i}(i=\overline{1, n})$, for each of the predicted values $\mathrm{y}(\mathrm{s}+\mathrm{t}), \mathrm{t}=\overline{1, \mathrm{~T}}$, puts three numeric evaluations: pessimistic, realistic and optimistic. Assign them, accordingly, $y_{i s+t}^{(p)}, y_{i s+t}^{(r)}, y_{i s+t}^{(o)}$. Let us consider that $y_{i s+t}^{(p)} \leq y_{i s+t}^{(r)} \leq y_{i s+t}^{(o)}$ without decreasing generality of considerations. Let the experts assign the degrees of confidence for each of their assessments. That is $\mu_{\mathrm{is}+\mathrm{t}}^{(\mathrm{p})}, \mu_{\mathrm{is}+\mathrm{t}}^{(\mathrm{r})}, \mu_{\mathrm{is}+\mathrm{t}}^{(\mathrm{o})}$ for pessimistic, realistic and optimistic assessment, accordingly. It is naturally to consider that $\mu_{\mathrm{is}+\mathrm{t}}^{(\mathrm{r})}>\mu_{\mathrm{is}+\mathrm{t}}^{(\mathrm{p})}$ and $\mu_{\mathrm{is}+\mathrm{t}}^{(\mathrm{r})}>\mu_{\mathrm{is}+\mathrm{t}}^{(\mathrm{o})}$.

In such setting, the problem boils down to the task of determining the numeric evaluation of the object and can be solved with the help of the rules $1-4$.

Define collective expert evaluations in $\tilde{y}_{\mathrm{e}}(\mathrm{s}+\mathrm{t}), \mathrm{t}=\overline{1, \mathrm{~T}}$.

Assume that with the help of certain method of time series forecasting we obtained forecasted values, which we define in $\tilde{y}_{\mathrm{f}}(\mathrm{s}+\mathrm{t}), \mathrm{t}=\overline{1, \mathrm{~T}}$.

Then the resulting values are calculated by the formula:

$$
y(s+t)=\alpha \tilde{y}_{e}(s+t)+(1-\alpha) \tilde{y}_{f}(s+t)
$$

where $\alpha \in[0 ; 1]$ is the value set by a person who makes decisions. This value expresses the level of impact of experts' assessments on the result of forecasting.

\section{Experimental validation of the research results}

Let us consider a problem of forecasting quantitative characteristics of HIV-infected people, officially registered in the region [13].

Values of these indicators in Zakarpatska Region in Ukraine over the period from 1987 to 2014 are given in Table 1.

To compare the results of forecasting by different methods, let us take the values from 1995 to 2009 as a learning sample. And we will compare the values from 2010 to 2014 to the results of forecasting.
Table 1

Values of the main quantitative characteristics of HIV-infected people, officially registered in the region [16]

\begin{tabular}{|c|c|c|}
\hline Year & $\begin{array}{l}\text { New cases of } \\
\text { HIV-infection }\end{array}$ & $\begin{array}{l}\text { Number of HIV-infected } \\
\text { by the end of the year }\end{array}$ \\
\hline $1987-1995$ & 6 & 6 \\
\hline 1996 & 10 & 8 \\
\hline 1997 & 27 & 35 \\
\hline 1998 & 21 & 51 \\
\hline 1999 & 20 & 63 \\
\hline 2000 & 17 & 77 \\
\hline 2001 & 26 & 94 \\
\hline 2002 & 12 & 91 \\
\hline 2003 & 10 & 77 \\
\hline 2004 & 14 & 73 \\
\hline 2005 & 36 & 100 \\
\hline 2006 & 22 & 109 \\
\hline 2007 & 43 & 136 \\
\hline 2008 & 42 & 154 \\
\hline 2009 & 50 & 185 \\
\hline 2010 & 62 & 221 \\
\hline 2011 & 63 & 251 \\
\hline 2012 & 82 & 288 \\
\hline 2013 & 81 & 322 \\
\hline 2014 & 83 & 370 \\
\hline
\end{tabular}

Let us solve this problem by the method of synthesis of forecasting scheme based on basic models [15]. Let us take auto regression method, method of least squares with weights, Brown method (linear and quadratic model), Winters method as the basic models.

To evaluate the quality of forecasting models (basic and synthesized by a forecasting scheme), the mean square error $(\Delta)$ and the average relative error $(\mu)$ are used for the different steps of forecasting $(\tau)$ that are calculated by the following formulas, accordingly:

$$
\begin{aligned}
& \Delta=\sqrt{\frac{\sum_{\mathrm{t}=1}^{\mathrm{n}}\left(\mathrm{v}_{\mathrm{t}}-\tilde{\mathrm{v}}_{\mathrm{t}}\right)^{2}}{\mathrm{n}},}, \\
& \mu=\frac{1}{\mathrm{n}} \sum_{\mathrm{t}=1}^{\mathrm{n}}\left|\frac{\mathrm{v}_{\mathrm{t}}-\tilde{\mathrm{v}}_{\mathrm{t}}}{\mathrm{v}_{\mathrm{t}}}\right|
\end{aligned}
$$

Values of forecasting errors are given in Tables 2, 3.

Table 2

\begin{tabular}{|c|c|c|c|c|c|c|}
\hline Error & $\begin{array}{c}\text { Auto re- } \\
\text { gression } \\
\text { method } \\
\text { (M1) }\end{array}$ & $\begin{array}{l}\text { Method } \\
\text { of least } \\
\text { squares } \\
\text { with } \\
\text { weights } \\
\text { (M2) }\end{array}$ & $\begin{array}{c}\text { Brown } \\
\text { method } \\
\text { of the } \\
1^{\text {st }} \text { order } \\
\text { (M3) }\end{array}$ & $\begin{array}{c}\text { Brown } \\
\text { method } \\
\text { of the } \\
2^{\text {nd }} \text { order } \\
\text { (M4) }\end{array}$ & $\begin{array}{l}\text { Winters } \\
\text { method }\end{array}$ & $\begin{array}{l}\text { Synthe- } \\
\text { sized } \\
\text { scheme }\end{array}$ \\
\hline$\Delta(\tau=1)$ & 6,2313 & 7,4416 & 12,0679 & 14,6251 & $1,7319^{*}$ & $1,7319^{*}$ \\
\hline$m(t=1)$ & 0,0729 & 0,093 & 0,1698 & 0,1966 & $0,020^{*}$ & $0,020^{*}$ \\
\hline$\Delta(\tau=3)$ & 5,8019 & 7,4416 & 12,0679 & 14,6251 & 1,8826 & $1,2813^{*}$ \\
\hline$\mu(\tau=3)$ & 0,0797 & 0,093 & 0,1698 & 0,1966 & 0,0200 & $0,0161^{*}$ \\
\hline$\Delta(\tau=5)$ & 3,0522 & 2,9564 & 11,4006 & 4,6924 & 1,6178 & $1,5240^{*}$ \\
\hline $\mathrm{m}(\mathrm{t}=5)$ & 0,032 & 0,0360 & 0,1273 & 0,0699 & 0,0174 & $0,0165^{*}$ \\
\hline
\end{tabular}

Values of forecasting errors for the indicator "New cases of HIV infection"

Note: $\Delta$ is the mean square error; $\mu$ is the average relative error; $\tau$ is the step of forecasting; * is the minimal value of an error for given step 
Value of forecasting errors for the indicator "Number of HIV-infected people by the end of the year"

\begin{tabular}{|l|c|c|c|c|c|c|}
\hline Error & $\begin{array}{c}\text { Auto re- } \\
\text { gression } \\
\text { method } \\
\text { (M1) }\end{array}$ & $\begin{array}{c}\text { Method } \\
\text { of least } \\
\text { squares } \\
\text { with } \\
\text { weights } \\
\text { (M2) }\end{array}$ & $\begin{array}{c}\text { Brown } \\
\text { method } \\
\text { of the } \\
1^{\text {st }} \text { order } \\
\text { (M3) }\end{array}$ & $\begin{array}{c}\text { Brown } \\
\text { method } \\
\text { of the } \\
2^{\text {nd }} \text { order } \\
\text { (M4) }\end{array}$ & $\begin{array}{c}\text { Winters } \\
\text { method }\end{array}$ & $\begin{array}{c}\text { Synthe- } \\
\text { sized } \\
\text { scheme }\end{array}$ \\
\hline $\mathrm{D}(\mathrm{t}=1)$ & 6,6538 & 65,1013 & 30,0312 & 31,7880 & 3,1241 & $\mathbf{2 , 2 1 9 5}^{*}$ \\
\hline $\mathrm{m}(\mathrm{t}=1)$ & 0,0288 & 0,2362 & 0,1060 & 0,1033 & 0,0127 & $\mathbf{0 , 0 0 8 5}^{*}$ \\
\hline $\mathrm{D}(\mathrm{t}=3)$ & 8,4229 & 65,1013 & 30,0312 & 31,7880 & $\mathbf{3 , 7 3 4 2}$ & $\mathbf{3 , 7 3 4 2}^{*}$ \\
\hline $\mathrm{m}(\mathrm{t}=3)$ & 0,0356 & 0,2362 & 0,1060 & 0,1033 & $\mathbf{0 , 0 1 5 0}$ & $\mathbf{0 , 0 1 5 0 ^ { * }}$ \\
\hline $\mathrm{D}(\mathrm{t}=5)$ & 9,01750 & 2,1504 & 27,7448 & 27,9098 & 4,2160 & $\mathbf{3 , 5 2 8 0}$ \\
\hline $\mathrm{m}(\mathrm{t}=5)$ & 0,0313 & 0,0053 & 0,0857 & 0,0798 & 0,0121 & $0,0120^{*}$ \\
\hline
\end{tabular}

Note: $\Delta$ is the mean square error; $\mu$ is the average relative error; $\tau$ is the step of forecasting; * is the minimal value of an error for given step

The results for indicators "New cases of AIDS" and "Number of AIDS patients by the end of the year" are similar. Since the best forecast is obtained with the help of synthesized forecasting scheme [15], then the results of forecasting of quantitative characteristics of HIV-positive people registered officially in the region by the synthesized forecasting scheme is taken as the basis. The results of the forecasting are in Fig. 1, 2 and in Table 4.

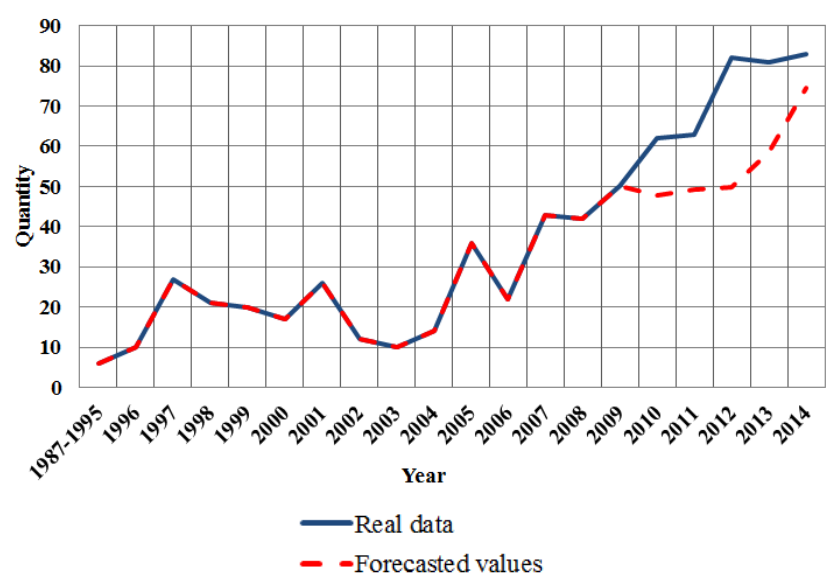

Fig. 1. New cases of HIV infection

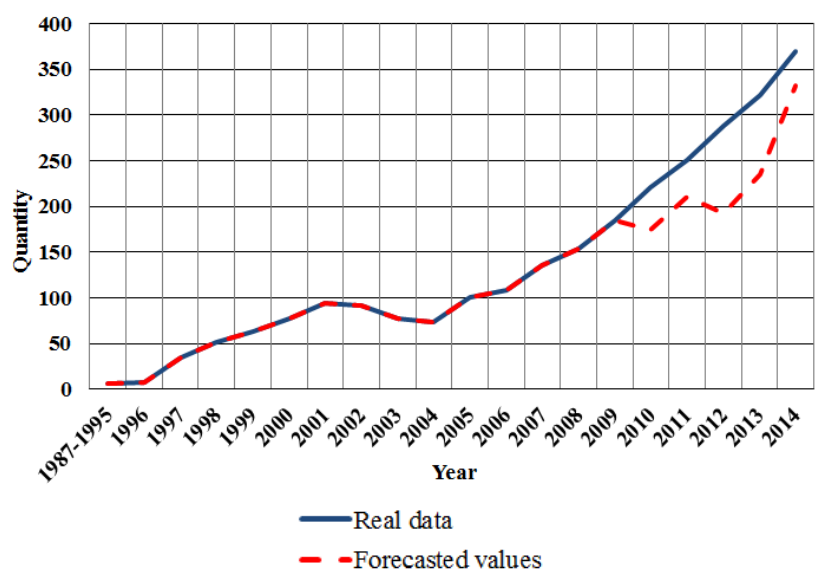

Fig. 2. Number of HIV-infected by the end of the year

In spite of the forecasting errors $\Delta$ and $\mu$ being insignificant, the real data differ significantly from the forecasted ones.
Forecasted values

\begin{tabular}{|c|c|c|c|}
\hline Category & $\begin{array}{c}\text { Step of fore- } \\
\text { casting (year) }\end{array}$ & Forecasting scheme & $\begin{array}{c}\text { Forecasted } \\
\text { values }\end{array}$ \\
\hline \multirow{3}{*}{$\begin{array}{l}\text { New cas- } \\
\text { es of HIV } \\
\text { infection }\end{array}$} & $\mathrm{t}=1(2010)$ & $\begin{array}{l}\tilde{\mathrm{v}}_{15+1}=0 * \tilde{\mathrm{v}}_{15+1}^{(1)}+0 * \tilde{\mathrm{v}}_{15+1}^{(2)}+ \\
+0^{*} \tilde{\mathrm{v}}_{15+1}^{(3)}+0^{*} \tilde{\mathrm{v}}_{15+1}^{(4)}+1^{*} \tilde{\mathrm{v}}_{15+1}^{(5)}\end{array}$ & 47,6806 \\
\hline & $\mathrm{t}=3(2012)$ & $\begin{array}{l}\tilde{\mathrm{v}}_{15+1}=0.14 * \tilde{\mathrm{v}}_{15+1}^{(1)}+0 * \tilde{\mathrm{v}}_{15+1}^{(2)}+ \\
+0 * \tilde{\mathrm{v}}_{15+1}^{(3)}+0^{*} \tilde{\mathrm{v}}_{15+1}^{(4)}+0.86^{*} \tilde{\mathrm{v}}_{15+1}^{(5)}\end{array}$ & 49,8674 \\
\hline & $\mathrm{t}=5(2014)$ & $\begin{array}{l}\tilde{\mathrm{v}}_{15+1}=0.23 * \tilde{\mathrm{v}}_{15+1}^{(1)}+0 * \tilde{\mathrm{v}}_{15+1}^{(2)}+ \\
+0 * \tilde{\mathrm{v}}_{15+1}^{(3)}+0^{*} \tilde{\mathrm{v}}_{15+1}^{(4)}+0.77^{*} \tilde{\mathrm{v}}_{15+1}^{(5)}\end{array}$ & 74,4492 \\
\hline \multirow{3}{*}{$\begin{array}{l}\text { The } \\
\text { number } \\
\text { of HIV- } \\
\text { infected } \\
\text { people by } \\
\text { the end } \\
\text { of the } \\
\text { year }\end{array}$} & $\mathrm{t}=1(2010)$ & $\begin{array}{l}\tilde{\mathrm{v}}_{15+1}=0.25^{*} \tilde{\mathrm{v}}_{15+1}^{(1)}+0 * \tilde{\mathrm{v}}_{15+1}^{(2)}+ \\
+0^{*} \tilde{\mathrm{v}}_{15+1}^{(3)}+0^{*} \tilde{\mathrm{v}}_{15+1}^{(4)}+0.75^{*} \tilde{\mathrm{v}}_{15+1}^{(5)}\end{array}$ & 174,9428 \\
\hline & $\mathrm{t}=3(2012)$ & $\begin{array}{l}\tilde{\mathrm{v}}_{15+1}=0 * \tilde{\mathrm{v}}_{15+1}^{(1)}+0 * \tilde{\mathrm{v}}_{15+1}^{(2)}+ \\
+0 * \tilde{\mathrm{v}}_{15+1}^{(3)}+0^{*} \tilde{\mathrm{v}}_{15+1}^{(4)}+1^{*} \tilde{\mathrm{v}}_{15+1}^{(5)}\end{array}$ & 192,9142 \\
\hline & $\mathrm{t}=5(2014)$ & $\begin{array}{l}\tilde{\mathrm{v}}_{15+1}=0.16^{*} \tilde{\mathrm{v}}_{15+1}^{(1)}+0 * \tilde{\mathrm{v}}_{15+1}^{(2)}+ \\
+0 * \tilde{\mathrm{v}}_{15+1}^{(3)}+0^{*} \tilde{\mathrm{v}}_{15+1}^{(4)}+0.84^{*} \tilde{\mathrm{v}}_{15+1}^{(5)}\end{array}$ & 332,5521 \\
\hline
\end{tabular}

Let us solve the problem by using a proposed method at $\mathrm{t}=1$. Compile a group of 5 experts $\mathrm{E}=\left\{\mathrm{E}_{1}, \mathrm{E}_{2}, \mathrm{E}_{3}, \mathrm{E}_{4}, \mathrm{E}_{5}\right\}$. Coefficients of their competence and the results of the expertise are given in Table 5 .

Table 5

Expert data

\begin{tabular}{|c|c|c|c|c|c|c|c|}
\hline Expert & $\alpha_{\mathrm{i}}$ & $\mathrm{y}_{\mathrm{i} 15+1}^{(\mathrm{p})}$ & $\mu_{\mathrm{i} 15+1}^{(\mathrm{p})}$ & $\mathrm{y}_{\mathrm{i} 15+1}^{(\mathrm{r})}$ & $\mu_{\mathrm{i} 15+1}^{(\mathrm{r})}$ & $\mathrm{y}_{\mathrm{i} 15+1}^{(\mathrm{o})}$ & $\mu_{\mathrm{i} 15+1}^{(\mathrm{o})}$ \\
\hline $\mathrm{E}_{1}$ & 0,2 & 50 & 0,2 & 58 & 0,9 & 62 & 0,3 \\
\hline $\mathrm{E}_{2}$ & 0,2 & 55 & 0,4 & 61 & 0,7 & 65 & 0,1 \\
\hline $\mathrm{E}_{3}$ & 0,2 & 50 & 0,1 & 59 & 0,8 & 65 & 0,2 \\
\hline $\mathrm{E}_{4}$ & 0,2 & 50 & 0,2 & 57 & 0,6 & 65 & 0,4 \\
\hline $\mathrm{E}_{5}$ & 0,2 & 55 & 0,2 & 62 & 0,8 & 65 & 0,1 \\
\hline
\end{tabular}

By using the rule 1 and the rule 2 to determine a numeric object evaluation, we form corresponding fuzzy sets $C_{1}=\left\{\left(x, M_{1}(x)\right)\right\}, C_{2}=\left\{\left(x, M_{2}(x)\right)\right\}$. Use (9) for setting the resulting forecasting data. Then collective expert evaluations will be as follows: $\tilde{y}_{1 \mathrm{e}}(\mathrm{n}+1) \approx 58,7, \tilde{\mathrm{y}}_{2 \mathrm{e}}(\mathrm{n}+1) \approx 60,385$.

As is seen from Table $4, \tilde{y}_{\mathrm{f}}(\mathrm{n}+1) \approx 47,680$. As the real value of the indicator "New cases of HIV infection" in 2010 is 62 , so it is evident that using the formula (13) at any $\alpha \in(0 ; 1)$ will improve the forecasting results.

Similarly one can determine the forecasted values of the indicator "Number of HIV-infected people by the end of the year" on the basis of expert assessments. The results of the forecasting by the proposed scheme depend on the competence of the expert group and the degree of the impact of the "expert block" on the final forecasting value, which is determined by a person who makes decisions.

\section{Discussion of the results of the research of methods of determining the numerical evaluation of the object}

Fuzzy model of the problem of determining collective numerical object evaluation is built, in which experts' conclusions are presented as the interval of change in evaluation taking into account the degrees of experts' confidence in their results. 
Applying proposed heuristics for the analysis of the results of experts' surveys allows disregarding the opinions of those experts, the degrees of confidence of which have certain features. Such mechanism provides decrease of the impact on the research from those experts who are not confident in their assessments or who are not able to detect the most probable one. The choice of the rule for setting the collective numerical object evaluation depends on the features of a person who makes decisions and on the problem character.

The model of forecasting was designed during the research that is a continuation of the forecasting scheme [15]. The numeric object assessments are used in it with the aim to provide a possibility to consider the external factors in the forecasting, which have a high impact on the forecasting value, but do not have systematic character or can't be formalized. Generally, such cases occur in the problems of forecasting social and economic phenomena.

The numeric experiment was carried out to fulfill the analysis of the efficiency of using the expert methods of determining collective object evaluation that showed that the application of methods which considered only internal features of the series leads to inaccurate forecasting values in the problem of forecasting the quantity of HIV-infected people in the region by the end of the year. However, using an "expert block" for this problem allowed applying the knowledge and experience of the experts and improving the forecasting results.

The advantage of the proposed approach is that at solving the problem of time series forecasting, it could be possible to simultaneously use mathematical, fuzzy, neural network methods of their forecasting with the use of time series forecasting and the numeric object evaluations as well as the results of experts' surveys.

The proposed scheme of forecasting is sensitive to the results of experts' surveys and depends on the competence of an expert group and a person who make decisions.

\section{Conclusions}

The research of the problem of determining the numeric object evaluation was performed. The aim of the research is a development of heuristic rules of determining the numeric assessment of the object based on the fuzzy experts' evaluations to improve the efficiency of decision making for the problems where the results of experts' surveys are used and which are related to the forecasting or evaluation of certain numeric characteristics of objects. During the research, the following was achieved:

1. A fuzzy mathematical model of the problem of determining the numeric object evaluation was built that allows presenting experts' conclusions as the interval of change in the evaluation considering the degrees of experts' confidence in the results.

2. Heuristic rules of determining the numeric object evaluation were compiled, which include the cases when the experts from an expert group are not confident in their assessments that allow reducing the impact of such factors on the expertise results.

3. A model of time series forecasting was built, based on the fuzzy methods of determining collective numeric evaluation of the object, which provides the possibility to consider both internal series trends and unsystematic and poor formalized external factors.

4. Experimental validation of the developed rules was performed on the example of the problem of forecasting the quantity of HIV-infected people registered officially in Zakarpatska Region. The efficiency and expedience of inclusion of an "expert block" during determining the forecasting values were demonstrated.

Therefore, the developed models and methods can be used effectively in both solving the problems of determining collective numeric evaluation of the object and forecasting the time series.

\section{References}

1. Voloshin, A. F. Problems of collective socially significant decisions [Text] / A. F. Voloshin, P. P. Antosyak // In XII-th International Conference, 2006. - 153 p.

2. Kaliszewski, I. Simple additive weighting-A metamodel for multiple criteria decision analysis methods [Text] / I. Kaliszewski, D. Podkopaev // Expert Systems with Applications. - 2016. - Vol. 54. - P. 155-161. doi: 10.1016/j.eswa.2016.01.042

3. Voloshin, O. The System of Quality Prediction on the Basis of a Fuzzy Data and Psychography of the Experts [Electronic resource] / O. Voloshin, M. Panchenko. - 2003. - Available at: http://hdl.handle.net/10525/946

4. Larichev, O. I. Properties of the decision-making methods in multicriteria problems of individual choice [Text] / O. I. Larichev // Automatic. Telemekh. - 2002. - Vol. 2. - P. 146-158.

5. Antosiak, P. P. Indirect approach of determination of collective alternative ranking on the basis of fuzzy expert judgements [Text] / P. P. Antosiak, O. F. Voloshin // Information technologies \& knowledge. - 2011. - P. 168.

6. Voloshyn, F. Fuzzy membership functions in a fuzzy decision making problem [Electronic resource] / A. Voloshyn, G. Gnatienko, E. Drobot. - 2003. - Available at: http://hdl.handle.net/10525/943

7. Hettiarachchi, C. Risk-based test case prioritization using a fuzzy expert system [Text] / C. Hettiarachchi, H. Do, B. Choi // Information and Software Technology. - 2016. - Vol. 69. - P. 1-15. doi: 10.1016/j.infsof.2015.08.008

8. Korchenko, O. G. Research priori estimation methods to implement an expert examination in the field of information security [Text] / O. G. Korchenko, D. A. Hornitskyy, T. G. Zaharchuk // Data Protection. - 2010. - Vol. 12, Issue 4 (49). - Available at: http://jrnl.nau.edu.ua/index.php/ZI/article/view/1976/1967

9. Janssen, J. Experts' views on digital competence: Commonalities and differences [Text] / J. Janssen, S. Stoyanov, A. Ferrari, Y. Punie, K. Pannekeet, P. Sloep // Computers \& Education. - 2016. - Vol. 68. - P. 473-481. doi: 10.1016/j.compedu.2013.06.008

10. Snityuk, V. E. Models and methods of determining the competence of experts on the basis of unbiasedness axiom [Text] $/$ V. E. Snityuk // News CHITI. - 2000. - Vol. 4. - P. 121-126.

11. Kolpakova, T. A. (2011). Determination of the competence of experts in making group decisions. Radioelektronika, computer science, upravlinnya, 1 (24), 40-43. 
12. Chang, Y. Nonstationarity in time series of state densities [Text] / Y. Chang, C. Sik Kim, J. Y. Park // Journal of Econometrics. 2016. - Vol. 192, Issue 1. - P. 152-167. doi: 10.1016/j.jeconom.2015.06.025

13. Geche, F., Mulesa, O., Myronyuk, I., Vashkeba, M. (). Forecasting quantitative characteristics of officially registered hiv-infected persons in the region [Text] / F. Geche, O. Mulesa, I. Myronyuk, M. Vashkeba // Technology audit and production reserves. 20154. - Vol. 4, Issue 2 (24). - P. 34-39. doi: 10.15587/2312-8372.2015.47907

14. Mulesa, O. Yu. Methods of considering the subjective character of input data in voting [Text] / O. Yu. Mulesa // Eastern-European Journal of Enterprise Technologies. - 2015. - Vol. 1, Issue 3 (73). - P. 20-25. doi: 10.15587/1729-4061.2015.36699

15. Geche, F. E. Development of synthesis method of predictive schemes based on basic predictive models [Text] / F. E. Geche, O. Yu. Mulesa, S. F. Geche, M. M. Vashkeba // Technology audit and production reserves. - 2015. - Vol. 3, Issue 2 (23). - P. 36-41. doi: $10.15587 / 2312-8372.2015 .44932$

16. HIV infection in Ukraine. Newsletter № 43 [Text]. - Kyiv, Health of Ukraine, Ukr. control center for socially dangerous diseases, 2015. -109 p.

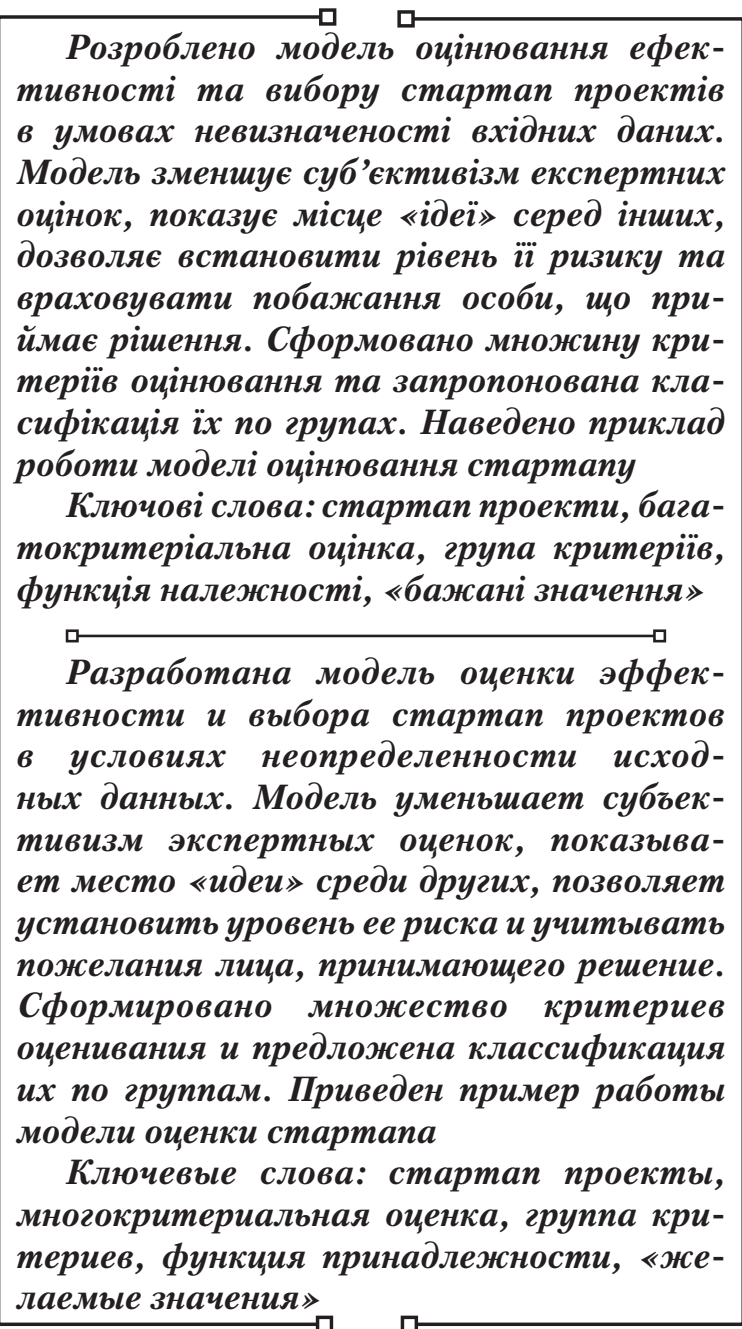

\section{Introduction}

With the development of information technologies and the globalization of the information society, the concept of a start-up develops, which is closely connected with the modern economy. Assessment of a start-up project is in the evaluation of an "idea", which may bring profits in future. The cost of such "idea" cannot be evaluated (commercially) without introducing it to the market. Yesterday's "bad idea" may turn successful today, due to the rapid changes in the industry or areas of business where it is implemented. In this regard, the problem (poorly structured now)
UDC 519.8

DOI: $10.15587 / 1729-4061.2016 .71222$

MODEL OF STARTUPS ASSESSMENT UNDER CONDITIONS OF INFORMATION UNCERTAINTY

\author{
M. Malyar \\ $\mathrm{PhD}$, Associate Professor* \\ E-mail: malyarmm@gmail.com \\ V.Polis h c h u k \\ $\mathrm{PhD}$, Lecturer \\ Department of Software Systems** \\ E-mail: v.polishchuk87@gmail.com \\ M. S h a r k adi \\ $\mathrm{PhD}$, Associate professor* \\ E-mail: marjancuk@mail.ru \\ I. L i a k h \\ $\mathrm{PhD}$, Lecturer \\ Department of Information science and \\ physics and mathematics disciplines** \\ E-mail: garik11@inbox.ru \\ *Department of Cybernetics and applied mathematics** \\ **Uzhgorod National University \\ Narodna sq., 3, Uzhgorod, Ukraine, 88000
}

of assessment of efficiency of start-up projects arises, the solution to which is interested for either venture funds or the startuppers themselves.

Any startup is a project at the level of "ideas", directed into the future by definition, and the project that has strategic character is directed into distant future. The future cannot be predicted at one hundred percent while the decision about the launch of implementation of the project (start-up) must be taken today. Therefore, there is an actual problem of the development of the models for the assessment of startups under conditions of information uncertainty. 